\title{
A Route Less Traveled: Principals' Perceptions of Alternative Licensed CTE Teachers
}

\author{
Scott R. Bartholomew (Corresponding Author) \\ Assistant Professor, Engineering/Technology Teacher Education \\ 351 Young Hall, Purdue University, West Lafayette, IN. 47905 \\ Email: sbartho@purdue.edu Tel: 765-494-7711 \\ Emma P. Bullock \\ Assistant Professor of Mathematics and Mathematics Education \\ Office 439G, Department of Mathematics and Statistics, \\ College of Science and Engineering Technology \\ Sam Houston State University, Huntsville, TX 77341 \\ Email: ebullock@shsu.edu Tel: 936-294-3816
}

Louis S. Nadelson

Director of Sponsored Programs and Academic Research

Colorado Mesa University, 1100 North Street, Grand Junction, CO 81501

Email: lnadelson@coloradomesa.edu Tel: 970-248-1424

Received: February 24, 2018

doi:10.5296/jet.v5i2.12503
Accepted: March 24, 2018

Published: April 18, 2018

URL: http://dx.doi.org/10.5296/jet.v5i2.12503

\begin{abstract}
The shortage of teachers prepared to teach career and technical education (CTE) courses, or willing to work in certain locations (e.g. inner city, rural), has motivated the desire to explore solutions such as alternative routes to teacher licensure (ARL). Most ARL programs bypass colleges of education and provide a different approach to preparing individuals to teach, leaving many to wonder about the quality and knowledge of these teachers. Specific areas, such as CTE, have seen a large influx of ARL teachers in recent years. We sought to determine school principals' perceptions of ARL CTE teachers. We found principal support for ARL teachers as well as perceptions of a lack of preparation and effectiveness when compared to traditionallyprepared teachers. We also found differences in perceptions of ARL teachers by the principals' school level and school SES level.
\end{abstract}

Keywords: CTE, ARL, teacher licensure, teacher preparation 


\section{Teacher Preparation}

The United States currently faces a K-12 teacher shortage (Lindqvist \& Nordanger, 2016). Traditionally, K-12 teachers are prepared in degree programs at institutions of higher education that are approximately four years in duration, include a combination of coursework and field experience (e.g., student teaching, internship), and thus prepare teachers to begin teaching immediately following graduation (National Education Association, 2016). However, the number of teachers graduating from higher education teacher preparation programs has not been adequate to meet the demands (Lindqvist \& Nordanger, 2016; National Education Association, 2016). Exasperating this, Fletcher, and colleagues (2015) report a decline in traditional Career and Technical Education (CTE) teacher preparation programs.

In efforts to alleviate teacher shortages, various alternative plans and pathways for teacher preparation have been explored, implemented, and evaluated (NRC, 2010). These alternative programs predominantly involve an alternative route or pathway to licensure which allows individuals to enter a classroom without an education degree (National Education Association, 2016). However, while research exploring the effectiveness and value of traditional versus alternative teacher preparation pathways exists (e.g., Darling-Hammond, 2000; NRC, 2010; Sass, 2014), the perceptions of key stakeholders, such as school principals, on alternative routes to licensure (ARL) effectiveness is unclear, especially with respect to CTE teachers (CottonFlanagan, 2011; Nusbaum, 2002). We sought to address the gap in the literature by exploring school principals' perceptions of CTE teachers who were prepared through ARL programs. In our exploratory research we sought to provide a foundation for exposing issues, trends, and needed direction for future research.

\subsection{ARL Versus Traditionally-Prepared CTE teachers}

Meeting the ongoing and expanding need for workers prepared for technical jobs requires preparation that begins in K-12 education. In the United States, approximately $94 \%$ of high school students are enrolled in CTE classes, which is, in part, motivated by the traditional goal of preparing students for technical careers (ACTE, 2016). With the high levels of student enrollment comes a demand for CTE teachers. Recent trends suggest that an increasing number of CTE teachers are entering the profession through an alternative route to licensure (Hoepfl, 2001). These increases in alternative route to licensure (ARL) CTE teachers come despite relatively little research into the perceptions and experience of school principals with regard to ARL CTE teacher preparation and effectiveness. Because principals are typically the individuals making the decisions to hire and retain teachers, their perceptions of ARL prepared teachers are important.

The majority of the existing reports of comparisons between ARL and traditional CTE teachers have focused on measures of teacher's self-efficacy (Duncan, Cannon, \& Kitchell, 2013). Some researchers have indicated that traditionally-prepared CTE teachers and ARL CTE teachers are not significantly different (Rocca \& Washburn, 2006), while others report that traditionallyprepared CTE teachers as more self-efficacious than their ARL CTE counterparts (Duncan, et al., 2013; Duncan \& Ricketts, 2008). Duncan and colleagues (2013) report that traditionallyprepared teachers had a higher perceived level of self-efficacy except when considering 
teaching using non-computer technology. Duncan and Ricketts (2008) found that traditionallyprepared teachers were more efficacious in their program management abilities while ARL teachers were more efficacious in their technical content knowledge. Similarly, there is evidence to support the notion that traditionally-prepared teachers are better prepared pedagogically while ARL teachers are more prepared with relation to content knowledge (Fletcher, \& Zirkle, 2011; Ruhland, \& Bremer, 2003). Arguments in favor of ARL teachers tend to cite ARL teachers' content knowledge as a bi-product of industry experience, which the individual brings with them when they transition from the workforce to the classroom (Duncan \& Ricketts, 2008; Fletcher, \& Zirkle, 2011). Conversely, Henry et al. (2014), argue that, although ARL programs offer an additional pathway and provide a means of alleviating the shortage of teachers, ARL teachers may be less-effective than their traditionally-prepared counterparts in certain subject areas.

As the responsibility of hiring and retaining teachers falls largely to the school principal (Hopkins, 2015), there is justification for us exploring school principals' perceptions of ARL and traditionally-prepared CTE teachers. Principals may encounter challenges in hiring CTE teachers with the capacity to effectively teach, manage a lab/shop space, maintain inventory and supplies, and collaborate with other teachers. More so, CTE includes multiple subjects and skill areas through a wide variety of courses which requires teachers with a range of technical preparation and skills (e.g., business, sewing, woodworking, metalworking, etc.). Thus, when hiring a new CTE teacher, principals must take into consideration knowledge, skills, experience, instructional ability, potential for collaboration, and prospect of successfully working with students (Fletcher, \& Zirkle, 2011). Our exploratory study provided a foundation for expanding what we know about the perceptions and knowledge principals hold regarding the potential for ARL teachers to effectively fulfill the expectations of CTE teachers.

\section{Methods}

Our overarching research question for our study was: What knowledge and perceptions do school principals' hold regarding ARL and traditionally-prepared CTE teachers? To guide our study we developed the following specific research questions:

- In comparison to other subject areas what are K-12 school principals' perceptions and hiring practices of alternatively licensed CTE teachers?

- Do K-12 school principals' perceptions of traditionally-prepared and alternatively licensed CTE teachers change with respect to the location or type of school where the principal works?

\section{1 Participants}

Thirty-nine K-12 principals from a state in the western United States participated in our survey (19 female, 20 male) with $81 \%$ in their principalship for 1-15 years. All 39 participants received traditional preparation as teachers. The principals were evenly split between urban (19) and suburban schools (20). Participants were distributed among the K-12 levels with 59\% working in elementary schools, $23 \%$ in middle schools, and $18 \%$ in high schools. 


\subsection{Survey Instruments}

Due to the exploratory nature of our research we could not rely on extant instruments for the data we were seeking to collect. Thus, we developed a basic demographic survey assessing principals' personal and professional variables based on our research questions. We then developed a survey containing 21 five-point Likert-scale items to assess the principals' perceptions and experiences with ARL and traditionally-prepared CTE teachers. Thus, all items on the perceptions and experiences survey were selected response. Our surveys included items such as, "I believe the classroom management of an ARL is as good as a traditionally-prepared teacher" and "I believe traditionally-prepared teachers are better prepared than ARL teachers" which the participants responded to using the Likert scale of 1 representing "strongly disagree" to 5 which represented "strongly agree" and a 3 representing "neutral." We validated the instrument by having each team member (all who had extensive K12 experience in teaching and/or administration) determine if the items were relevant to teacher hiring of performance. Once we all agreed that the items were aligned with our research goals we considered the instrument to have contract validity. We calculated the Cronbach alpha reliability to be .89 indicating an acceptable level of reliability for the survey.

\subsection{Data Collection}

We recruited school leaders using the current list of principals publically available through the state Office of Education and through school district websites. After gaining appropriate district permissions all principals were contacted by email and provided a link to the survey. All data collection took place on-line, was anonymous, and voluntary.

\section{Results}

Our first research question asked, In comparison to other subject areas what are K-12 school principals 'perceptions and hiring practices of alternatively licensed CTE teachers? To answer this question we conducted a series of single sample t-tests to determine if the values were significantly above or below "neutral" on the Likert scale which was represented by a value of 3. We were seeking to determine if the principals had perceptions that were significant below neutral which would indicate a negative perception, or significantly above neutral which would indicate a positive perception (see Table 1).

We found differences in principals' perceptions of the traditionally-prepared teachers and ARL teachers in relation to their classroom practices (e.g. items 9 and 16) and level of preparation (e.g. items 3, 15, and 21). 
Table 1. Mean Response and Test for Significance by Item to the Neutral Value $\left(H_{0}=3\right)(n=39)$

\begin{tabular}{ll}
\hline \multicolumn{1}{c}{ Item } \\
\hline 1. How likely are you to hire an ARL teacher? \\
2. ARL candidates contribute to a more diverse teaching workforce. \\
3. What is your perception of the preparation of ARL teachers to teach? \\
4. What is your level of experience working with ARL teachers? \\
5. From your knowledge or perceptions, how well do ARL teachers work
\end{tabular}
with other teachers?

6. The experience ARL teachers bring to the classroom inspires students.

7. ARL adapt quickly to the culture of schools?

\begin{tabular}{llll} 
Mean & SD & \multicolumn{1}{c}{$\mathbf{t}$} & Sig \\
\hline 2.90 & .91 & -.70 & .49 \\
3.46 & .82 & 3.51 & $.00^{*}$ \\
2.41 & .82 & -4.50 & $.00^{*}$ \\
3.38 & 1.02 & 2.36 & $.02 *$ \\
3.33 & .66 & 3.14 & $.00 *$ \\
3.18 & .88 & 1.27 & .21 \\
3.38 & .94 & 2.57 & $.01 *$ \\
2.08 & 1.01 & -5.71 & $.00^{*}$ \\
& & & \\
3.62 & .88 & 4.38 & $.00 *$
\end{tabular}

9. ARL teachers take more effort to support than traditionally-prepared teachers.

10. ARL teachers are important to meeting the educational mission of our schools?

11. ARL teachers tend to work well with students.

12. I believe a teacher's effectiveness is related to the preparation they've received for teaching.

2018, Vol. 5, No. 2

3. ARL teachers are less likely to have a long-term commitment to the teaching profession than traditionally-prepared teachers.

14. I avoid hiring an ARL unless it is my last option.

15. I believe traditionally prepared teachers are better prepared than ARL teachers.

16. I believe the classroom management of an ARL is as good as a traditionally-prepared teacher.

17. ARL teachers cost more money to train than traditionally-prepared teachers.

18. ARL teachers are retained at the same rate as traditionally-prepared teachers.

19. Parents see no difference between ARL and traditionally-prepared teachers.

20. Students see no difference between ARL and traditionally-prepared teachers.

21. When compared with other subjects, ARL teachers in CTE areas are less prepared.

22. When compared with other subjects, ARL teachers in CTE areas are less professional

$\begin{array}{llll}3.05 & .94 & .34 & .74\end{array}$

$3.31 \quad .69 \quad 2.77 \quad .01 *$

$3.62 \quad .81 \quad 4.72 \quad .00 *$

$2.69 \quad .86 \quad-2.23 \quad .03 *$

$\begin{array}{llll}3.00 \quad 1.12 & .00 \quad 1.00\end{array}$

$\begin{array}{llll}3.56 \quad .82 & 4.29 \quad .00 *\end{array}$

$2.54 \quad .97 \quad-2.97 \quad .01 *$

$2.69 \quad .73 \quad-2.63 \quad .01 *$

$\begin{array}{llll}2.92 & .84 & .57 & .57\end{array}$

$\begin{array}{llll}3.33 & .90 & 1.60 & .12\end{array}$

$\begin{array}{llll}3.46 \quad .85 & 3.38 \quad .00 *\end{array}$

$\begin{array}{llll}3.67 \quad .92 & 3.77 \quad .00^{*}\end{array}$

$\begin{array}{llll}3.31 & .79 & 1.99 & .06\end{array}$

23. When compared with other subjects, ARL teachers in CTE areas are less capable.

24. When compared with other subjects, ARL teachers in CTE areas are less work.

$* \mathrm{p}<.05$ 
Principals were neutral in terms of ARL teachers' impact on school culture or climate, but also indicated that ARL teachers are not their first choice. Principals indicated that ARL teachers adapt quickly to school culture and tend to work well with students. Our analysis also revealed that the principals thought that the ARL candidates contribute to a more diverse workforce. See Table 1 for the survey items, mean response (on a 5-pont Likert scale), the t-statistic $\left(\mathrm{H}_{0}=3\right.$, response is neutral) and the significance.

Through our analysis we exposed two significant correlations among the principals' responses to our survey items. The first significant correlation $(r=.55, p<.01)$ was between the level to which principals indicated that they tended to avoid hiring ARL teachers (item 14) and the level of principals' perceptions that teacher effectiveness is related to their preparation (item 12). The second significant relationship $(r=.64, p<.01)$ was between the principals' level of avoidance of hiring ARL teachers (item 14) and the principals' level of perception of an increased need for support of ARL teachers (item 9). We interpret these findings to suggest that principals who tend to avoid hiring ARL teacher do so because they perceive that the ARL teachers have a greater potential lack of effectiveness due to an inadequate preparation to teach. Further, we interpret that principals may tend to avoid hiring ARL teachers because they may perceive the teachers as needing more support.

Our second research question asked, Do K-12 school principals' perceptions of traditionallyprepared and ARL CTE teachers change with respect to the location or type of school where the principal works? We found there was no difference in the responses based on the location of the school (e.g. urban compared to suburban) but did find differences when using the grade level of the schools as the factor of analysis. High school principals indicated that students tend to see no difference with ARL teachers to a much higher degree $(M=3.33, S=.52)$ than both elementary $(M=2.36, S=.79)$ and middle school principals $(M=2.22, \mathrm{~S}=.83) F(2,34)=4.48$, $p=.019$. Similarly, we found that high school principals $(M=4.17, S=.41)$ perceive ARL teachers are prepared to teach at a higher level than middle school principals $(M=3.00, S=.87)$ $F(2,34)=4.89, p=.014$. We also found a relationship when considering the SES level of the principals' schools as a factor with respect to effectiveness of teachers based on their preparation $F(3,35)=4.58, p<.01$, the avoidance of hiring ARL teachers $F(3,35)=3.55, p$ $=.02$, and with parents seeing no difference with ARL teachers $F(3,35)=3.30, p=.03$. Thus, it seems that when compared to principals of schools in high SES areas, principals in schools in lower SES areas perceive higher levels of ARL teacher effectiveness, are more likely to hire an ARL teacher, and work with parents who are less likely to see (or voice) a difference between traditional and ARL prepared teachers.

\section{Discussion and Implications}

The goal of our exploratory research was to provide a foundation for additional research to address the question raised by Nagy and Wang (2007) about school principals' perceptions of alternately licensed teachers. Thus, we investigated principals' perceptions with regards to ARL CTE teachers as CTE has experienced a large influx of ARL teachers in recent years (CottonFlanagan, 2011). We found that, in general, principals tended to be supportive of hiring and working with ARL teachers and at the same time recognized the potential for these teachers to 
have lower levels of preparation and effectiveness than traditionally-prepared teachers. We speculate that many ARL teachers attracted to teaching are likely to focus on areas that are difficult to fill (e.g. mathematics and science) or seek teaching positions in regions or locations where teacher recruitment and retention is a challenge. We also posit that ARL teachers tend to demonstrate high levels of content and skill knowledge, that principals may perceive as effective for overcoming the lack of instructional preparation. Further, we conjecture that principals in the schools where ARL teachers are hired are likely to be more tolerant and supportive of ARL teachers because of the need to hire and retain teachers in their schools. Gaining a deeper understanding of the reasons for principal acceptance of teachers who may be less well prepared and effective than traditionally-prepared teachers is a direction for our future research.

Our finding that principals' working in schools from different community types (e.g. rural, urban) did not differ in their responses suggests that other variables are likely to be more predictive of principals' perceptions of ARL teachers, such as grade levels. The difference in perceptions by grade level suggests that as ARL teachers may focus on content and skills they may be better suited for high school than earlier grades where a wider range of student developmental needs are addressed as well as less emphasis on content-area knowledge. Our explanation is supported by our finding that indicates that high school principals were significantly higher in their perceptions that ARL teachers are prepared to teach compared to the perceptions of the middle school and elementary school principals.

We speculate that the difference in perceptions of principals based on the SES of their schools was due to the challenges associated with recruiting and retaining highly qualified and experienced teachers and the potential to attract and be selective of teachers. Many teachers find the challenges associated with working with students and families in lower SES area too demanding and therefore tend to seek teaching positions in schools in higher SES areas. Because of teacher preferences of schools in higher SES areas, principals in lower SES areas may develop different standards for assessing teaching quality and therefore, may be more tolerant of teachers with limited content knowledge and instructional capacity. Having the flexibility to be more selective allows principals (in potentially high SES neighborhoods) to choose teachers (ARL or traditional) who they perceived to be the best prepared and potentially highly effective. In contrast, principals working in schools that are challenged to attract and retain teachers (in potentially lower SES neighborhoods) have less flexibility and cannot be as selective and, therefore, may be faced with hiring teachers (ARL or traditional) who are potentially less effective and less prepared, and therefore may be more tolerant of the teachers.

The correlations we found support our speculation that how principals perceive levels of ARL teacher preparation influences their consideration for hiring teachers who are alternatively prepared. Thus, we reason that if principals perceive ARL prepared teachers to be less effective or needing more support they will tend to avoid hiring these teachers. Again, gaining a deeper understanding of the experience and interactions that influence principal perceptions of ARL prepared teachers is a direction for future research. 


\section{Limitations}

The first limitation of our study is the limited sample size and the constraint to a single region in one state in the United States. A larger sample size that included participants from a broader region may result in different data. However, our data did reveal some consistent trends and some results that are aligned with the literature and met our expectation for this exploratory study. Collecting similar data with a broader sample of principals, from a diversity of regions, would be an excellent direction for future research.

The second limitation of our study is the lack of qualitative data to provide context for the answers to our survey items. Thus, we are not sure why the principals answered the way they did and what their thoughts were about the ARL and traditionally-prepared teachers. Gathering qualitative data associated with principals' perceptions of ARL teachers is an important consideration for future research.

\section{Conclusion}

Alternative licensed teachers have become an integral part of many school systems as the related programs continue to grow in availability. Alternative licensed teachers are particularly common in CTE as many of these teachers come from business and industry to consider education as a second career. School principals' perceptions of the preparation and capacity of ARL teachers is fundamental to their hiring and success. While we found variations in principals' perceptions based on SES, school grade level, and personal experience, there remain several unknowns about the perceptions of principals of ARL teachers that warrant further investigation. Our exploratory work has laid a foundation for additional research and has provided some potentially fruitful directions for future investigation as we continue to explore the most effective ways of meeting the demands for highly effective CTE teachers.

\section{References}

ACTE. (2016). CTE basics. Retrieved on May 9, 2016 from https://www.acteonline.org/cte/

Cotton-Flanagan, K. (2011). A study on becoming an alternatively certified career and technical educator. Dissertations. Paper 361. Retrieved on May 9, 2016 from http://scholarworks.wmich.edu/dissertations/361

Darling-Hammond, L. (2000). How teacher education matters. Journal of Teacher Education, 51(3), 166-173, https://doi.org/10.1177/0022487100051003002

Duncan, D. W, \& Ricketts, J. (2008). Total program efficacy: A comparison of traditionally and alternatively certified agriculture teachers. Journal of Agriculture Education, 49(4), 3846, https://doi.org/10.5032/jae.2008.04038

Duncan, D. W., Cannon, J., \& Kitchel, A. (2013). Teaching efficacy: A comparison of traditionally and alternatively certified CTE teachers in Idaho. Career and Technical Education Research, 38(1), 57-67. https://doi.org/10.5328/cter38.1.57 
Fletcher, E. C., \& Zirkle, C. (2011). Career and technical education's role in alternative teacher licensure. In V. Wang (Ed.), Definitive Readings in the History, Philosophy, Theories and Practice of Career and Technical Education (pp. 84-102). Hershey, PA: Information Science Reference. https://doi.org/10.4018/978-1-61520-747-3.ch006

Fletcher, E. C., Jr., Gordon, H. R. D., Asunda, P., \& Zirkle, C., (2015). A 2015 status study of career and technical education programs in the United States. Career and Technical Education Research, 40(3), 191-211, https://doi.org/10.5328/cter40.3.191

Henry, G. T., Purtell, K. M., Bastian, K. C., Fortner, C. K., Thompson, C. L., Campbell, S. L., \& Patterson, K. M. (2014). The effects of teacher entry portals on student achievement. Journal of Teacher Education, 65(1), 7-23. https://doi.org/10.1177/0022487113503871

Hoepfl, M. (2001). Alternative routes to certification of technology education teachers. The Journal of Technology Studies, 27(2), 35-44, https://doi.org/10.21061/jots.v27i2.a.2

Hopkins, G. (2015). What qualities do principals look for in a new teacher? EducationWorld. Retrieved on May 9, 2016 from http:/www.educationworld.com/a_admin/admin/ admin071.shtml

Lindqvist, P. \& Nordanger, U.K. (2016). Already elsewhere - A study of (skilled) teachers' choice to leave teaching. Teaching and Teacher Education, 54, 88-97, https://doi.org/10.1016/j.tate.2015.11.010

Nagy, C.J., \& Wang, N. (2007). The alternate route teachers' transition to the classroom: preparation, support, and retention. National Association of Secondary School Principals Bulletin, 91(1), 98-113, https://doi.org/10.1177/0192636506299153

National Education Association (2016). Research spotlight on alternative routes to teacher certification. Retrieved on May 5, 2016 from http://www.nea.org/tools/16578.htm

National Research Council (2010). Preparing teachers: Building evidence for sound policy. Washington, DC: National Academies Press.

Nusbaum, C. (2002). Principals' perceptions of the effectiveness of alternatively certified and traditionally certified teachers in Hampton Roads Virginia. Thesis. Retrieved on May 9, 2016 from https://theses.lib.vt.edu/theses/available/etd-12092002-183209/unrestricted/ Chp4-5.PDF

Rocca, S.J. \& Washburn, S.G. (2013). Comparison of teacher efficacy among traditionally and alternatively certified agriculture teachers, Journal of Agriculture Education, 47(3), 5869. https://doi.org/10.5032/jae.2006.03058

Ruhland, K.S., Bremer, C.D. (2003). Perceptions of Traditionally and Alternatively Certified Career and Technical Education Teachers. Journal of Vocational Education Research, 28(3), 285-302, https://doi.org/10.5328/JVER28.3.285

Sass, T.R. (2014). Licensure and Worker Quality: A Comparison of Alternative Routes to Teaching. Journal of Law and Economics, 58(1), 1-35. https://doi.org/10.1086/682904 


\section{Copyright Disclaimer}

Copyright reserved by the author(s).

This article is an open-access article distributed under the terms and conditions of the Creative Commons Attribution license (http://creativecommons.org/licenses/by/3.0/). 